\title{
AN EXAMINATION OF THE NEED FOR SPERM CAPACITATION IN THE TURKEY, MELEAGRIS GALLOPAVO*
}

\author{
B. HOWARTH, JR AND M. B. PALMER \\ Department of Poultry Science, University of Georgia, Athens, Georgia 30601, U.S.A.
}

(Received 6th Fuly 1971, accepted 5th October 1971)

Since the recognition by Austin (1951) and Chang (1951) that rabbit spermatozoa require a period of time within the female tract before they are capable of fertilizing ova, evidence has accumulated suggesting an essential period of capacitation for spermatozoa in many other mammals: rat (Austin, 1951; Noyes, 1953; Austin \& Braden, 1954), ferret (Chang \& Yanagimachi, 1963), hamster (Chang \& Sheaffer, 1957; Barros, 1968a, b), cat (Hamner, Jennings \& Sojka, 1970) and sheep (Mattner, 1963). The question therefore arises as to whether capacitation is a general phenomenon in all vertebrates. In the fowl, Gallus domesticus, the period of time required by spermatozoa in the female tract is of a short duration since cock spermatozoa can fertilize eggs within a few minutes of insemination (Bobr, Ogasawara \& Lorenz, 1964). Furthermore, spermatozoa introduced into the infundibulum and ovarian pocket of the fowl $15 \mathrm{~min}$ after oviposition and just before ovulation produce fertile eggs (Olsen \& Neher, 1948). Recent observations based on successful fertilization in vitro of fowl ova with freshly collected spermatozoa indicate that cock spermatozoa do not require a period of capacitation within the hen's reproductive tract in order to fertilize ova (Howarth, 1970). The purpose of the present study was to determine whether turkey spermatozoa require a period of capacitation in order to fertilize ova, using the same test system in vitro as that used in the previous investigation dealing with the fowl (Howarth, 1970).

Recently ovulated ova were obtained from Large White turkey hens. Prediction of the time of ovulation was based on knowledge of the time of oviposition. Ovulation of the succeeding ovum in Beltsville Small White turkeys usually occurs on average $30 \mathrm{~min}$ after oviposition (Wolford, Ringer \& Coleman, 1964). In the present study, it was found necessary to wait for approximately $45 \mathrm{~min}$ after oviposition to increase the likelihood of obtaining recently ovulated ova.

One group of three ova, referred to as control ova, were recovered from the magnum of artificially inseminated hens killed $85 \mathrm{~min}$ after oviposition and were then cultured in vitro for $24 \mathrm{hr}$. The time of recovery was chosen to allow sufficient time for ovulation and fertilization to occur in vivo before recovery. Ova in this group were used to evaluate the ability of the culturing system to support development in vitro. A second group of five ova served as negative controls. They were recovered from the infundibulum of unmated hens killed

* University of Georgia, College of Agriculture Experiment Stations, Journal Series Paper No. 1126, College Station, Athens. 
$45 \mathrm{~min}$ after oviposition and cultured in vitro for $24 \mathrm{hr}$. This (negative control) group of ova was used to determine the extent of parthenogenetic development of cultured ova from unmated hens. A third group of five ova, referred to as treated ova, were obtained from the infundibulum of unmated hens killed $45 \mathrm{~min}$ after oviposition. An attempt was then made to fertilize these ova in vitro followed by a 24-hr culture period in vitro identical with that imposed upon the control ova. The culture procedure used in this study has been described previously (Howarth, 1970). All ova were suspended initially in modified Ringer's solution (Olsen \& Neher, 1948). In addition, $0.1 \mathrm{ml}$ of recently collected semen diluted 1:300 in modified Ringer's solution was placed directly over the germinal discs of all treated ova in the third group. All ova were then incubated at $41^{\circ} \mathrm{C}$ for $15 \mathrm{~min}$. Following this short incubation period, which was considered sufficient to allow for fertilization in vitro, the Ringer's solution was removed and all ova were resuspended in freshly collected albumen. The ova were then incubated for an additional $24 \mathrm{hr}$ at $41^{\circ} \mathrm{C}$.

Following the incubation period, the blastodiscs of all ova were removed and placed in Bouin's fixative. The blastodiscs were then embedded in paraffin wax, sectioned at $6 \mu \mathrm{m}$, and stained with Delafield's haematoxylin. Stained sections were examined microscopically to determine fertilization rates and the extent to which embryonic development had progressed. The presence of darkly stained nuclei and organized cellular proliferation represented by single layered sheets of cells were used as the criteria of fertilization. By contrast, the parthenogenetic development of newly laid, unfertilized turkey eggs has been depicted by Olsen (1965) as being represented by compact unorganized masses of cells (varying greatly in size and shape) located near the centre of the protoplasmic disc.

An examination of the blastodiscs of control ova revealed that two out of three were fertile. One fertile blastodisc was in the blastula stage of development. The other fertile blastodisc showed signs of organized cellular proliferation but was lacking a segmentation cavity or blastocoele (Pl. 1, Fig. 1). By contrast, the remaining unfertilized egg contained numerous vacuoles in its uncleaved protoplasmic disc (Pl. 1, Fig. 2). These preliminary results indicate that the system used was capable of supporting development in vitro.

The attempt to fertilize recently ovulated ova in vitro was successful. Two of the five blastodiscs removed from treated ova and examined microscopically were found to be fertile. Of the two fertile blastodiscs, one was in the blastula stage (Pl. 1, Fig. 3) while the other, which was apparently retarded, had not progressed beyond the early cleavage stage of development. The possibility of

\section{EXPLANATION OF PLATE 1}

Fig. 1. Median cross-section of a fertile blastodisc removed from a control ovum. Note the presence of epithelial-type cells (E) and the absence of a well-defined segmentation cavity or blastocoele. $\times 740$.

Fig. 2. Median cross-section of an infertile disc removed from a control ovum. Note the presence of large vacuoles $(\mathrm{V})$ in the uncleaved protoplasm. $\times 740$.

Fic. 3. Median cross-section of a fertile blastodisc removed from a treated ovum which had been fertilized in vitro. The photomicrograph shows a section of the blastoderm containing epithelial-type cells (E) and a well-defined segmentation cavity (SG) located between the blastoderm and the underlying yolk. $\times 740$. 
PLATE 1

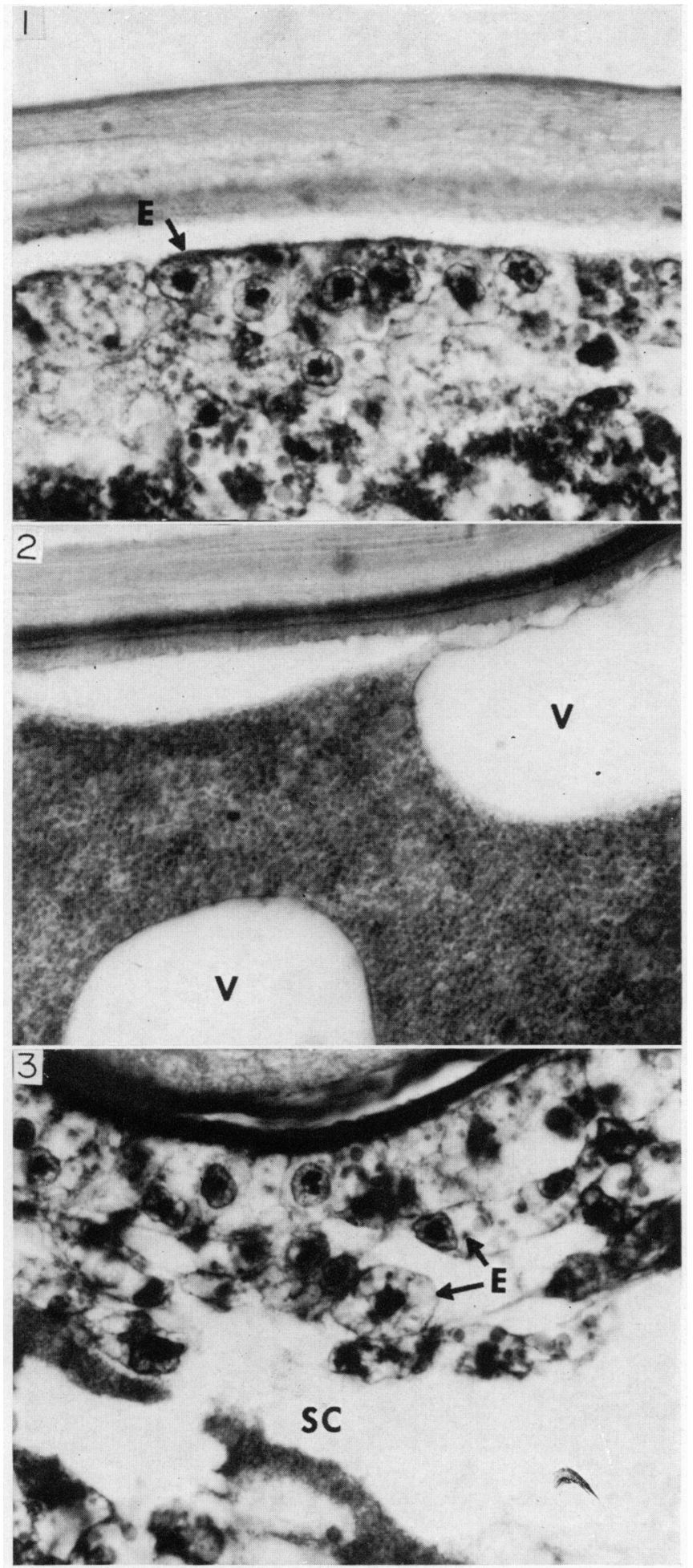


development occurring as a result of parthenogenesis was not substantiated in the present investigation as none of the five negative control ova recovered from unmated hens and cultured for $24 \mathrm{hr}$ in vitro showed signs of organized development. Microscopic examination of one of these blastodiscs revealed what appeared to be an unorganized group of enlarged blastomeres near the centre of the protoplasmic disc, but no nuclei were present. The remaining four negative control ova contained numerous vacuoles in their uncleaved protoplasmic discs and were similar in appearance to the unfertilized control egg depicted in Pl. 1, Fig. 2.

These preliminary observations indicate that turkey spermatozoa, like cock spermatozoa, do not require a period of capacitation within the female reproductive tract in order to fertilize ova.

\section{REFERENGES}

Austin, C. R. (1951) Observations on the penetration of the sperm into the mammalian egg. Aust. $\mathcal{F}$. scient. Res. B, 4, 581 .

Austin, C. R. \& Braden, A. W. H. (1954) Time relations and their significance in the ovulation and penetration of eggs in rats and rabbits. Aust. F. biol. Sci. 7, 179.

BARRos, G. (1968a) In vitro capacitation of golden hamster spermatozoa with Fallopian tube fluid of the mouse and rat. F. Reprod. Fert. 17, 203.

BARRos, G. (1968b) In vitro capacitation of golden hamster spermatozoa. (Abstract). Anat. Rec. 160, 310.

Bobr, W. L., Ogasawara, F. X. \& Lorenz, F. W. (1964) Distribution of spermatozoa in the oviduct and fertility in domestic birds. II. Transport of spermatozoa in the fowl oviduct. F. Reprod. Fert. $8,49$.

Chang, M. G. (1951) Fertilizing capacity of spermatozoa deposited into the Fallopian tubes. Nature, Lond. 168, 697.

Chang, M. G. \& Sheaffer, D. (1957) Number of spermatozoa ejaculated at copulation, transported into the female and present in the male tract of the golden hamster. F. Hered. 48, 107.

Ghang, M. C. \& Yanagimachi, R. (1963) Fertilization of ferret ova by deposition of epididymal sperm into the ovarian capsule with special reference to the fertilizable life of ova and the capacitation of sperm. F. exp. Zool. 154, 175.

HAMner, C. E., Jennings, L. L. \& SojkA, N. J. (1970) Cat (Felis catus L.) spermatozoa require capacitation. F. Reprod. Fert. 23, 477.

Howarth, B., JR (1970) An examination for sperm capacitation in the fowl. Biol. Reprod. 3, 338.

MATTNER, P. E. (1963) Capacitation of ram spermatozoa and penetration of the ovine egg. Nature, Lond. 199, 772.

Noyes, R. W. (1953) The fertilizing capacity of spermatozoa. West. F. Surg. Obstet. Gynec. 61, 342.

Orsen, M. W. (1965) Delayed development and atypical cellular organization in blastodiscs of unfertilized turkey eggs. Devl Biol. 12, 1.

Olsen, M. W. \& Neher, B. H. (1948) The site of fertilization in the domestic fowl. F. exp. Zool. 109, 355.

Wolford, J. H., Ringer, R. K. \& Coleman, T. H. (1964) Ovulation and egg formation in the Beltsville Small White turkey. Poultry Sci. 43, 187. 